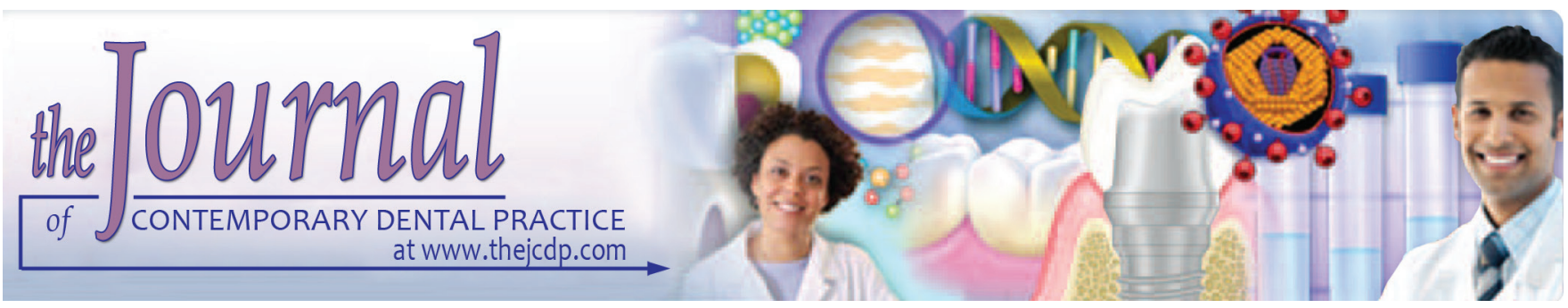

\title{
Influences of Light-emitting Diode Illumination Bleaching Technique on Nanohardness of Computer-aided Design and Computer-aided Manufacturing Ceramic Restorative Materials
}

\author{
${ }^{1}$ Niwut Juntavee, ${ }^{2}$ Apa Juntavee, ${ }^{3}$ Phuwiwat Saensutthawijit
}

\begin{abstract}
Aim: This study evaluated the effect of light-emitting diode (LED) illumination bleaching technique on the surface nanohardness of various computer-aided design and computer-aided manufacturing (CAD/CAM) ceramic materials.
\end{abstract}

Materials and methods: Twenty disk-shaped samples (width, length, and thickness $=10,15$, and $2 \mathrm{~mm}$ ) were prepared from each of the ceramic materials for CAD/CAM, including Lava ${ }^{\mathrm{TM}}$ Ultimate $\left(L_{V}\right)$, Vita Enamic ${ }^{\circledR}\left(E_{n}\right)$ IPS e.max ${ }^{\circledR} \operatorname{CAD}\left(M_{e}\right)$, inCoris ${ }^{\circledR}$ TZI $\left(I_{C}\right)$, and Prettau ${ }^{\circledR}$ zirconia $\left(P_{r}\right)$. The samples from each type of ceramic were randomly divided into two groups based on the different bleaching techniques to be used on them, using $35 \%$ hydrogen peroxide with and without LED illumination. The ceramic disk samples were bleached according to the manufacturer's instruction. Surface hardness test was performed before and after bleaching using nanohardness tester with a Berkovich diamond indenter.

Results: The respective Vickers hardness number upon no bleaching and bleaching without or with LED illumination [mean \pm standard deviation (SD)] for each type of ceramic were as follows: $102.52 \pm 2.09,101.04 \pm 1.18$, and $98.17 \pm 1.15$ for $L_{V}$ groups; $274.96 \pm 5.41,271.29 \pm 5.94$, and $268.20 \pm 7.02$ for $E_{n}$ groups; $640.74 \pm 31.02,631.70 \pm 22.38$, and $582.32 \pm 33.88$ for $M_{e}$ groups; $1,442.09 \pm 35.07,1,431.32 \pm 28.80$, and 1,336.51 \pm 34.03 for $I_{C}$ groups; and 1,383.82 $\pm 33.87,1,343.51 \pm 38.75$,

${ }^{1}$ Department of Prosthodontics, Faculty of Dentistry, Khon Kaen University, Khon Kaen, Thailand

${ }^{2}$ Department of Pediatric Dentistry, Faculty of Dentistry, Khon Kaen University, Khon Kaen, Thailand

${ }^{3}$ Division of Biomaterial Research, Faculty of Dentistry, Khon Kaen University, Khon Kaen, Thailand

Corresponding Author: Niwut Juntavee, Department of Prosthodontics, Faculty of Dentistry, Khon Kaen University, Khon Kaen, Thailand, Phone: +66897112980, e-mail: niwutpapa@ hotmail.com and 1,295.96 \pm 31.29 for $P_{r}$ groups. The results indicated surface hardness reduction following the bleaching procedure of varying degrees for different ceramic materials. Analysis of variance (ANOVA) revealed a significant reduction in surface hardness due to the effect of bleaching technique, ceramic material, and the interaction between bleaching technique and ceramic material $(p<0.05)$.

Conclusion: Bleaching resulted in a diminution of the surface hardness of dental ceramic for CAD/CAM. Using 35\% hydrogen peroxide bleaching agent with LED illumination exhibited more reduction in surface hardness of dental ceramic than what was observed without LED illumination.

Clinical significance: Clinicians should consider protection of the existing restoration while bleaching.

Keywords: Bleaching, Ceramic, Hardness, Illumination, Laboratory research, Light-emitting diode.

How to cite this article: Juntavee $N$, Juntavee $A$, Saensutthawijit P. Influences of Light-emitting Diode Illumination Bleaching Technique on Nanohardness of Computer-aided Design and Computer-aided Manufacturing Ceramic Restorative Materials. J Contemp Dent Pract 2018;19(2):196-204.

Source of support: The authors would like to thank Khon Kean University, Ministry of Education, Royal Thai Government, for providing financial support for this study.

Conflict of interest: None

\section{INTRODUCTION}

Esthetic dentistry is the branch of dentistry sciences related to dental treatment designed to satisfy the eye of the beholder by making the teeth look more appealing. Esthetic appearance in dentistry is primarily governed by the color of the teeth. The treatment amendments for unattractive teeth color are generally aimed at improving self-confidence, and in turn, the personality of the patient. Esthetic dental treatment for discolored teeth can be 
performed by following several approaches, for instance, enamel microabrasion, bleaching, veneering with porcelain or resin composite, and full-coverage restoration through a crown. Among all of these outlined approaches, bleaching has become a prevalent treatment in recent years because of its conservative treatment approach designed to achieve an optimum esthetic appearance. ${ }^{1}$ The bleaching procedure that requires bleaching agents to be used to whiten natural dentition was introduced by Haywood and Heymann. ${ }^{2}$ Nowadays, bleaching agents are commercially provided in the form of hydrogen peroxide or its compounds, such as carbamide peroxide. The mechanism followed by bleaching agents for the decoloring of the tooth structure entails the decomposition of the peroxide molecules into unstable free radicals. These free radicals can attack the large pigmented molecules that precipitate into the dental tissues and diverge them into smaller molecules that are easily diffusible. This process takes place through an oxidation or a reduction reaction, and it results in a whitening effect. ${ }^{3}$

Bleaching can be classified as vital and nonvital tooth bleaching or in-office or at home depending on the procedure performed. The bleaching products are generally found in the form of gels or paste containing 30 to $35 \%$ hydrogen peroxide, which is meant to be used for in-office bleaching procedure, whereas 6 to $20 \%$ carbamide peroxide is recommended for at-home bleaching procedure. ${ }^{4}$ Yet, there are many tooth-whitening products available in the market, which contain inconsistent concentrations of hydrogen peroxide that varies for different designs, such as whitening strip, paint-on bleaching product, or preformed bleaching tray. The in-office bleaching technique usually uses a high concentration of bleaching agent and is applied to tooth structure for a short period of time because the product is capable of producing more peroxide radicals, hence accelerating the bleaching process. The other popular approach for the in-office bleaching technique is using light in association with the bleaching process. Different light sources are introduced to use in combination to the bleaching, for instance, blue halogen lights, blue plasma arc lamp, LED, or light amplification by stimulated emission of radiation (lasers), such as diode laser, erbium-doped yttrium aluminum garnet laser, and $\mathrm{CO}_{2}$ laser. The light is processed for promoting the bleaching reaction by accelerating the release of hydroxyl-free radicals and by intensifying the oxidation-reduction reaction. ${ }^{5,6}$ Basically, the dentine is responsible for discolored structure of the discolored tooth, and hence, the hydrogen peroxide bleach needs to penetrate through the enamel to reach the discolored dentin. The infiltration capability of the bleaching agent is influenced by several factors, including diffusion capability, concentration of the bleaching agent, duration of the bleaching, and the number of the bleaching processes used. The efficacy of the bleaching is also related to the resistance of the tooth structure against the diffusion ability of hydroxyl-free radicals for generating oxidation-reduction reaction on the discolored structure. Tooth bleaching is considered to be comparatively safer in terms of the involved potential risks to the harmful tooth structure. ${ }^{7,8}$ This consideration is substantiated by clinical evidence that suggests that no macroscopic damage from bleaching has been identified. On the contrary, resorptions of tooth surface in the cervical area and the microscopic alteration of the tooth structure were reported due to exposure to bleaching agents, especially when bleaching agents were used in high concentrations. ${ }^{9,10}$

Ceramics have been popular as restorative materials in dentistry due to their esthetics-enhancing effects and biocompatibility. The technological advancements in the CAD/CAM in dentistry have been commenced by dental clinicians and researchers for developing new ceramic biomaterials that can render high-quality and reliable restorations with good prognosis. ${ }^{11}$ Several types of ceramic materials have been developed to meet the demands of both patients and dentists for highly esthetic and natural appealing restorations. Several ceramic-based materials have recently been introduced for CAD/CAM dentistry, including resin nano ceramic, hybrid ceramic, interpenetrating phase ceramic, lithium disilicate glass ceramic, yttria-stabilized tetragonal zirconia polycrystalline, monolithic zirconia, and zirconia-containing lithium silicate ceramics. ${ }^{12}$ These newly developed ceramic restorative materials are the fruit of the revolution in the technological approaches, and these offer the appropriate ceramic material property to clinicians for different treatment procedures that provide ease of restoration fabrication through CAD/CAM technology.

Most patients who need tooth whitening might already have some kind of restoration in their mouth. On bleaching, the bleaching agents may lead to alterations in the surface morphology as well as in the physical and chemical properties of the existing dental restorative materials. ${ }^{13,14}$ However, the free radicals released from the bleaching agents are extremely reactive, unstable, and prone to inducing acidic environment during bleaching. This is described as the main cause behind the adverse effects due to structural changes of the restorative materials, and this might lead to material failure. ${ }^{15,16}$ The difference in the bleaching materials and the techniques exerts different impacts on different restorative materials. ${ }^{17-19}$ Although traditional dental ceramics are considered to be the most inert dental restorative material among others, their surfaces were reported to manifest surface deterioration on contact with some acidulated materials, such as fluoride gels and other solutions. ${ }^{20,21}$ Hence, there 
is a possibility that free radicals of hydrogen ion $\left(\mathrm{H}^{+}\right)$or oxonium ion $\left(\mathrm{H}_{3} \mathrm{O}^{+}\right)$produced from the bleaching agents may cause dissolution in the ceramic glass networks and the leaching of alkali ions component of dental ceramics.

Surface hardness is one of the most important physical properties of a restorative material. Several studies have evaluated the effects of bleaching agents on the microhardness of resin-based restorative materials. However, these studies have produced incongruous results. Some studies reported a decrease in the surface microhardness after the bleaching process, ${ }^{22,23}$ while others did not. ${ }^{24-26} \mathrm{~A}$ few studies have also been conducted on the effects of the bleaching agent on the surface hardness of various dental ceramic materials. ${ }^{27}$ In addition, there is no report in the existing literature regarding the influence of highly concentrated bleaching agents on dental ceramics, especially the newly developed ceramic materials for CAD/CAM in dentistry. The effect of different bleaching techniques with LED illumination on the nanohardness of different types of ceramic used for the CAD/CAM system has not been reported elsewhere. Therefore, the objective of this study was to evaluate the in vitro effects of $35 \%$ hydrogen peroxide used in conjunction with LED illumination on surface nanohardness of different types of ceramic restorative materials used for CAD/CAM. The null hypothesis stated that bleaching techniques using 35\% hydrogen peroxide either with or without LED illumination does not affect the surface nanohardness of different CAD/ CAM ceramic restorative materials.

\section{MATERIALS AND METHODS}

This study investigated different types of ceramic materials that were resin nano ceramic which is Lava ${ }^{\mathrm{TM}}$ Ultimate $\left(\mathrm{L}_{\mathrm{V}} ; 3 \mathrm{M}\right.$ ESPE, St. Paul, Minnesota, USA), hybrid ceramic which is Vita Enamic ${ }^{\circledR}\left(\mathrm{E}_{\mathrm{n}}\right.$; VITA North America Inc., Yoba Linda, California, USA), lithium disilicate glass ceramic which is IPS e.max ${ }^{\circledR} \mathrm{CAD}\left(\mathrm{M}_{\mathrm{e}}\right.$; Ivoclar Vivadent, Schaan, Lichtenstein), and zirconia ceramic including inCoris ${ }^{\circledR} \mathrm{TZI}$
( $\mathrm{I}_{\mathrm{c}}$; Sirona Dental Systems GmbH, Bensheim, Germany) and Prettau ${ }^{\circledR}$ zirconia ( $\mathrm{P}_{\mathrm{r}}$; Zirkonzahn Inc., Atlanta, Georgia, USA). Each type of ceramic was bleached with $35 \%$ hydrogen peroxide (Pola office, SDI, Bayswater, Victoria, Australia) using two techniques, which included bleaching with and without LED illumination (BT-cool, APOZA Enterprise, New Taipei, Taiwan) (Table 1).

\section{Sample Preparation}

Each type of ceramic sample was prepared into a rectangular disk-shape with the dimension of width, length, and thickness equal to $10 \times 15 \times 2 \mathrm{~mm}$. Twenty disk specimens from each type of ceramic material were prepared.

\section{Resin Nano Ceramic and Hybrid Ceramic Sample Preparation}

Samples were prepared from the resin nano ceramic and hybrid ceramic material, which included Lava Ultimate $\left(\mathrm{L}_{\mathrm{V}}\right)$ and Vita Enamic $\left(\mathrm{E}_{\mathrm{n}}\right)$. The ceramic blanks were cut into disk shapes using a diamond-coated wheel (Isomet ${ }^{\circledR}$ 1000, Beuhler, Lake Bluff, Illinois, USA). The samples were then ground flat and polished with a silicon carbide abrasive paper at 800, 1,000, and 2,000 grit particles with a polishing machine $\left(\right.$ Ecomet $^{\circledR} 3$ polisher, Beuhler, Lake Bluff, Illinois, USA) to achieve the required dimension.

\section{Lithium Disilicate Ceramic Sample Preparation}

The presintered IPS e.max ${ }^{\circledR}$ CAD blank was cut into a disk-shaped sample and ground flat as previously described to achieve the required sample dimension. The presintered IPS e.max ${ }^{\circledR}$ CAD disk sample was coated with a thin layer of IPS e.max ${ }^{\circledR}$ CAD crystal (Ivoclar Vivadent, Schaan, Lichtenstein) and then sintered to achieve crystallization and glazing surface in a porcelain furnace (Programmat ${ }^{\circledR}$ P100, Ivoclar Vivadent, Schaan, Lichtenstein) according to the firing schedule recommended by the manufacturer.

Table 1: Ceramic materials and bleaching agent used in the study

\begin{tabular}{|c|c|c|}
\hline Product & Materials & Chemical composition \\
\hline \multirow[t]{2}{*}{ Lava $^{\mathrm{TM}}$ ultimate } & Resin nano ceramic & $\begin{array}{l}\text { Filler: } 80 \% \text { by weight of agglomerated zirconia-silica nanoparticles, individual-based } \\
\text { zirconia and silica nanoparticles }\end{array}$ \\
\hline & & Matrix: $20 \%$ by weight of highly cross-linked polymer \\
\hline \multirow[t]{2}{*}{ Vita Enamic ${ }^{\circledR}$} & Hybrid ceramic & Filler: $86 \%$ by weight of fine structure feldspathic ceramic \\
\hline & & Matrix: $14 \%$ by weight of polymer \\
\hline $\begin{array}{l}\text { IPS e.max }{ }^{\circledR} \\
\text { CAD }\end{array}$ & $\begin{array}{l}\text { Lithium disilicate } \\
\text { ceramic }\end{array}$ & $\begin{array}{l}\mathrm{SiO}_{2} 57-80 \%, \mathrm{Li}_{2} \mathrm{O} 11-19 \%, \mathrm{~K}_{2} \mathrm{O} 0-13 \%, \mathrm{P}_{2} \mathrm{O}_{5} 0-11 \%, \mathrm{ZrO}_{2} 0-8 \%, \mathrm{ZnO} 0-8 \% \text {, } \\
\text { colorant } 0-12 \%\end{array}$ \\
\hline InCoris ${ }^{\circledR} \mathrm{TZI}$ & Zirconia oxide ceramic & $\mathrm{ZrO}_{2}+\mathrm{HFO}_{2}+\mathrm{Y}_{2} \mathrm{O}_{3} \geq 99 \%, \mathrm{Y}_{2} \mathrm{O}_{3}>4.5-<6.0 \%, \mathrm{HfO}_{2} \leq 5 \%, \mathrm{Al}_{2} \mathrm{O}_{3} \leq 0.5 \%$, other oxide $\leq 0.5 \%$ \\
\hline $\begin{array}{l}\text { Prettau }{ }^{\circledR} \\
\text { zirconia }\end{array}$ & Zirconia oxide ceramic & $\begin{array}{l}\mathrm{ZrO}_{2}+\mathrm{HfO}_{2} \text { as main component, } \mathrm{Y}_{2} \mathrm{O}_{3} 4.95-5.26 \%, \mathrm{Al}_{2} \mathrm{O}_{3} 0.15-0.35 \%, \mathrm{SiO}_{2} \leq 0.02 \% \\
\mathrm{Fe}_{2} \mathrm{O}_{3} \leq 0.01 \%, \mathrm{Na}_{2} \mathrm{O}_{3} \leq 0.04 \%\end{array}$ \\
\hline \multirow[t]{2}{*}{ Pola office } & $35 \%$ Hydrogen peroxide & Liquid: $35 \%$ Hydrogen peroxide, $65 \%$ water \\
\hline & & Powder: Thickeners $75.26 \%$, catalysts $26.2 \%$, dye $0.04 \%$, desensitizing agents $0.5 \%$ \\
\hline
\end{tabular}




\section{Zirconia Sample Preparation}

The presintered zirconia samples were prepared into a rectangular disk shape from each type of zirconia material, which included InCoris ${ }^{\circledR}$ TZI $\left(I_{c}\right)$ and Prettau ${ }^{\circledR}$ zirconia $\left(\mathrm{P}_{\mathrm{r}}\right)$. The presintered zirconia blanks were cut into disk shapes and then ground flat as previously described to achieve the dimension that was approximately $12.5 \mathrm{~mm}$ in width, $19.3 \mathrm{~mm}$ in length, and $2.5 \mathrm{~mm}$ in thickness. This dimension was predetermined to compensate for the $20 \%$ volumetric shrinkage observed after the sintering process. Thereafter, all presintered zirconia samples were sintered in a sinter furnace (inFire ${ }^{\circledR}$ HTC, Sirona Dental Systems $\mathrm{GmbH}$, Bensheim, Germany), according to the manufacturer recommendations to attain the required shape and dimension.

After the samples from each type of ceramic were prepared, they were cleaned for 5 minutes in an ultrasonic bath, and then, they were stored in distilled water at $37^{\circ} \mathrm{C}$ for 24 hours. The baseline nanohardness of the samples were determined before the bleaching process. All samples for each type of ceramic materials were randomly divided into two groups (10 samples for each group) on which the two bleaching techniques were performed.

\section{Bleaching Techniques}

Before each bleaching procedure, samples in the experimental group were taken out from the distilled water bath and dried with air jet spray for 60 seconds. Thereafter, the bleaching techniques were performed according to the manufacturer instructions at room temperature $\left(25^{\circ} \mathrm{C}\right)$. The bleaching techniques were performed as follows:

\section{Technique 1: Bleaching without LED Illumination $\left(B_{N L}\right)$}

Newly mixed 35\% hydrogen peroxide was applied to the top surfaces of the sample, using a microbrush. Bleaching was performed according to the manufacturer recommendation. The bleaching agent was applied on the ceramic surface for 8 minutes. Thereafter, the bleaching agent was washed out with water jet spray for 60 seconds. Then, the bleaching agent was applied again as described previously for four times. Thus, each ceramic sample was attacked by the bleaching agent for 32 minutes.

\section{Technique 2: Bleaching with LED Illumination $\left(B_{L}\right)$}

Newly mixed $35 \%$ hydrogen peroxide was applied to the top surfaces of the sample, using a microbrush. Bleaching was performed in conjunction with LED illumination for 8 minutes. Thereafter, the bleaching agent was washed out with water jet spray for 60 seconds. The bleaching agent was applied again four times as described previously in conjunction with LED illumination. Thus, each ceramic sample was exposed to the bleaching agent and LED illumination for 32 minutes. On the conclusion of bleaching, all samples were stored in distilled water at $37^{\circ} \mathrm{C}$ for 24 hours before the determination of surface hardness using the nanoindentation test.

\section{Nanohardness Measurement}

Nanoindentation testing was performed with a Berkovich diamond indenter (Fig. 1) in a nanoindentation machine (IBIS nanoindentation system, Fisher-Cripps Laboratory Pty. Ltd., Forestville, New South Wales, Australia) to create an indented image on the sample surface both before and after the bleaching process. The nanoindentation test was performed in accordance to the nanoindentation protocol. ${ }^{28}$ The sample was placed on a metal platform with the tested surface facing the Berkovich diamond indenter (Fig. 1). The indents were made using the force controlled test at a rate of $10 \mathrm{~nm} / \mathrm{s}$. The test was performed at $30 \mathrm{mN}$ load for the Lava Ultimate ${ }^{\mathrm{TM}}$ and Vita Enamic ${ }^{\circledR}, 50 \mathrm{mN}$ load for the $\operatorname{IPS}^{\circledR}$ e.max CAD, and $100 \mathrm{mN}$ load for inCoris ${ }^{\circledR}$ TZI and Prettau ${ }^{\circledR}$ Zirconia. The time of loading was 15 seconds for reaching the indentation average depths of $500 \mathrm{~nm}$. Each sample was subjected to the determination of surface hardness both before and after the bleaching (eight indents for each) at different locations. Thereafter, the Vickers hardness number (VHN) at each indentation was measured.

\section{Scanning Electron Microscope Photomicrograph Evaluation}

The ceramic samples from each group were submitted to investigation to determine surface characteristics and the compared surface alteration before and after the bleaching process. The samples were dried, coated with gold by the sputtering technique, and observed with a scanning

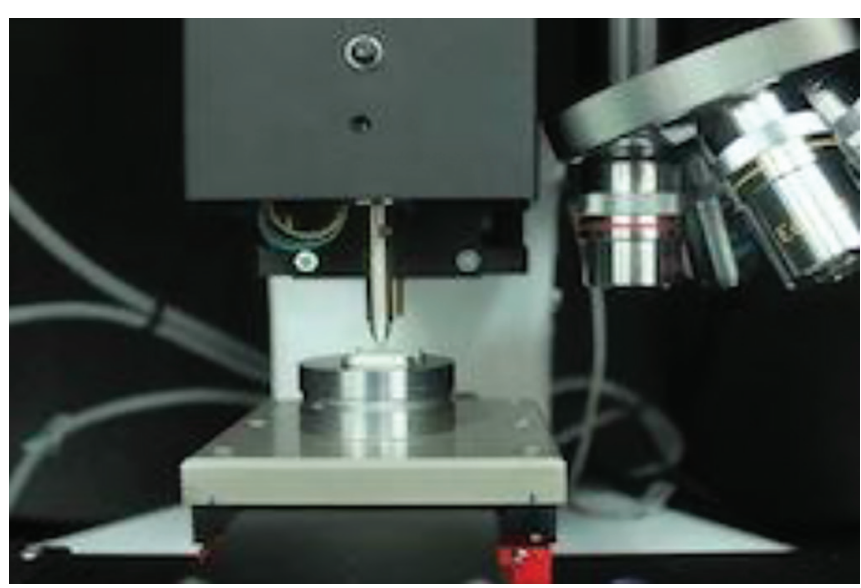

Fig. 1: Ceramic sample was placed on metal stand, indented with Berkovich diamond indenter on the nanohardness testing machine 
Table 2: Mean, SD, and 95\% Cl of VHN of ceramic materials for CAD/CAM before and after bleaching process

\begin{tabular}{|c|c|c|c|c|c|c|}
\hline \multirow[b]{3}{*}{ Group } & \multirow[b]{3}{*}{$n$} & \multirow[b]{3}{*}{ Ceramic } & \multirow{3}{*}{$\begin{array}{l}\text { Bleaching } \\
\text { method }\end{array}$} & \multicolumn{3}{|c|}{ VHN } \\
\hline & & & & \multirow[b]{2}{*}{ Mean $\pm S D$} & \multicolumn{2}{|c|}{ 95\% Confidence interval } \\
\hline & & & & & Lower limit & Upper limit \\
\hline $\mathrm{L}_{\mathrm{v}} \mathrm{N}_{\mathrm{B}}$ & 20 & Lava $^{\mathrm{TM}}$ Ultimate & $\mathrm{N}_{\mathrm{B}}$ & $102.52 \pm 2.09$ & 91.28 & 113.75 \\
\hline $\mathrm{L}_{v} \mathrm{~B}_{\mathrm{NL}}$ & 10 & Lava $^{\mathrm{TM}}$ Ultimate & $\mathrm{B}_{\mathrm{NL}}$ & $101.04 \pm 1.18$ & 85.16 & 116.93 \\
\hline $\mathrm{L}_{\mathrm{v}} \mathrm{B}_{\mathrm{L}}$ & 10 & Lava $^{\mathrm{TM}}$ Ultimate & $\mathrm{B}_{\mathrm{L}}$ & $98.17 \pm 1.15$ & 82.28 & 114.05 \\
\hline $\mathrm{E}_{\mathrm{n}} \mathrm{N}_{\mathrm{B}}$ & 20 & Vita Enamic ${ }^{\circledR}$ & $\mathrm{N}_{\mathrm{B}}$ & $274.96 \pm 5.41$ & 263.73 & 282.2 \\
\hline $\mathrm{E}_{\mathrm{n}} \mathrm{B}_{\mathrm{NL}}$ & 10 & Vita Enamic $^{\circledR}$ & $\mathrm{B}_{\mathrm{NL}}$ & $271.29 \pm 5.94$ & 255.27 & 287.06 \\
\hline $\mathrm{E}_{\mathrm{n}} \mathrm{B}_{\mathrm{L}}$ & 10 & Vita Enamic $^{\circledR}$ & $\mathrm{B}_{\mathrm{L}}$ & $268.20 \pm 7.02$ & 252.31 & 284.09 \\
\hline $\mathrm{M}_{\mathrm{e}} \mathrm{N}_{\mathrm{B}}$ & 20 & IPS e.max ${ }^{\circledR}$ CAD & $\mathrm{N}_{\mathrm{B}}$ & $640.74 \pm 31.02$ & 629.50 & 651.97 \\
\hline $\mathrm{M}_{\mathrm{e}} \mathrm{B}_{\mathrm{NL}}$ & 10 & IPS e.max ${ }^{\circledR}$ CAD & $\mathrm{B}_{\mathrm{NL}}$ & $631.70 \pm 22.38$ & 615.81 & 647.58 \\
\hline $\mathrm{M}_{\mathrm{e}} \mathrm{B}_{\mathrm{L}}$ & 10 & IPS e.max ${ }^{\circledR}$ CAD & $\mathrm{B}_{\mathrm{L}}$ & $582.32 \pm 33.88$ & 566.44 & 598.21 \\
\hline $\mathrm{I}_{C} \mathrm{~N}_{\mathrm{B}}$ & 20 & InCoris ${ }^{\circledR} \mathrm{TZI}$ & $\mathrm{N}_{\mathrm{B}}$ & $1,442.09 \pm 35.07$ & $1,430.85$ & $1,453.32$ \\
\hline $\mathrm{I}_{\mathrm{C}} \mathrm{B}_{\mathrm{NL}}$ & 10 & InCoris ${ }^{\circledR} \mathrm{TZI}$ & $\mathrm{B}_{\mathrm{NL}}$ & $1,431.32 \pm 28.80$ & $1,415.43$ & $1,447.20$ \\
\hline $\mathrm{I}_{\mathrm{C}} \mathrm{B}_{\mathrm{L}}$ & 10 & InCoris ${ }^{\circledR} \mathrm{TZI}$ & $\mathrm{B}_{\mathrm{L}}$ & $1,336.51 \pm 34.03$ & $1,320.62$ & $1,352.39$ \\
\hline $\mathrm{P}_{\mathrm{r}} \mathrm{N}_{\mathrm{B}}$ & 20 & Prettau $^{\circledR}$ & $\mathrm{N}_{\mathrm{B}}$ & $1,383.82 \pm 33.87$ & $1,372.59$ & $1,395.06$ \\
\hline $\mathrm{P}_{\mathrm{r}} \mathrm{B}_{\mathrm{NL}}$ & 10 & Prettau $^{\circledR}$ & $\mathrm{B}_{\mathrm{NL}}$ & $1,343.51 \pm 38.75$ & $1,327.62$ & $1,359.39$ \\
\hline $\mathrm{P}_{\mathrm{r}} \mathrm{B}_{\mathrm{L}}$ & 10 & Prettau $^{\circledR}$ & $B_{L}$ & $1,295.96 \pm 31.29$ & $1,280.03$ & $1,311.85$ \\
\hline
\end{tabular}

electron microscope (Hitachi, Tokyo, Japan). The scanning electron microscope photomicrographs for each group were investigated.

\section{Statistical Analysis}

The collected data were statistically analyzed using Statistical Package for the Social Sciences software for Windows (version 17, SPSS Inc., Chicago, Illinois, USA). The Kolmogorov-Smirnov test was used to evaluate the normal distribution of data. The results of the test showed normal distribution of data $(p>0.05)$, and therefore, the data were concluded to be parametric. The data of surface nanohardness of different groups were analyzed by ANOVA. Tukey multiple comparison test was used to achieve pairwise comparisons among groups of ceramic material and bleaching procedure. The statistical significance was determined at the $95 \%$ level of confidence.

\section{RESULTS}

The means value of hardness and SD of different groups are presented in Table 2 and Graph 1. Two-way ANOVA was used to compare the mean nanohardness values of the ceramic materials taking into account the effect of the bleaching methods and the ceramic materials used at 95\% level of confidence. The results indicated significant differences in the nanohardness of ceramic materials, which was the effect of the method of bleaching used and the type of ceramic materials tested $(p<0.05)$ as summarized in Table 3. Likewise, there was a significant difference in the surface nanohardness of ceramic materials that could be attributed to the interaction between ceramic materials and the bleaching technique $(p<0.05)$. Post hoc Tukey multiple comparison test indicated that there were significant differences in the surface hardness among the different groups of ceramic materials $(\mathrm{p}<0.05)$ as summarized in Table 4. Post hoc Tukey multiple comparison also

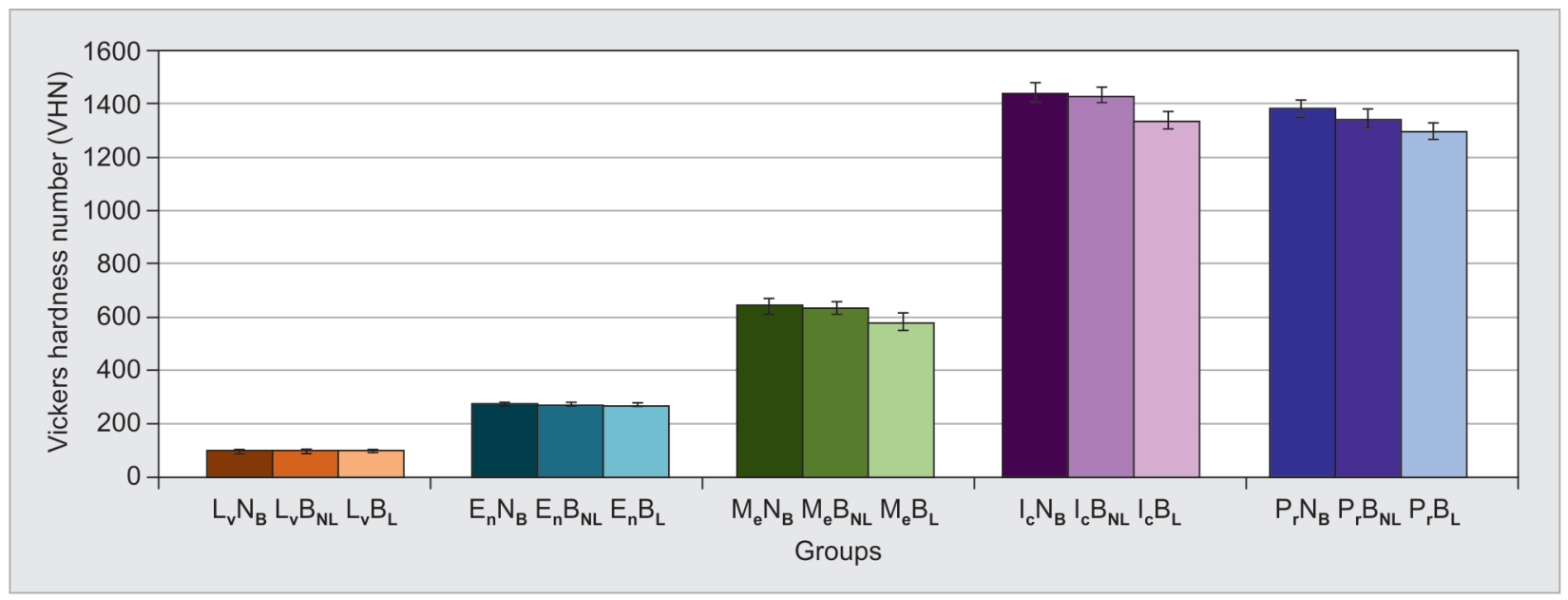

Graph 1: Vickers hardness number of different ceramic materials for CAD/CAM before and after bleaching with different bleaching techniques 
Influences of LED Illumination Bleaching on Nanohardness of CAD and CAM

Table 3: ANOVA of Vickers nanohardness of different dental ceramic for CAD/CAM system on different bleaching techniques

\begin{tabular}{llllll}
\hline Source & Sum of square & Degree of freedom & Mean of square & $f$-value & $p$-value \\
\hline Corrected model & $58,830,470.553$ & 14 & $4,202,176.467$ & $6,479.612$ & 0 \\
Intercept & $100,424,158.3$ & 1 & $100,424,158.35$ & $154,850.61$ & 0 \\
Ceramic & $51,994,055.886$ & 4 & $12,998,513.722$ & $20,043.263$ & 0 \\
Bleaching & $92,954.215$ & 2 & $46,477.108$ & 71.666 & 0 \\
Ceramic*Bleaching & $62,229.573$ & 8 & $7,778.697$ & 11.994 & 0 \\
Error & $119,976.727$ & 185 & 648.523 & & \\
Total & $172,174,006.0$ & 200 & & & \\
Corrected total & $58,950,447.260$ & 199 & & & \\
\hline
\end{tabular}

Table 4: Tukey post hoc multiple comparison of ceramic surface nanohardness related to the effect of different ceramic materials

\begin{tabular}{llllll}
\hline & Lava & Enamic & e.max & InCoris & Prettau \\
\hline Lava & 1.000 & & & & \\
Enamic & 0 & 1.000 & & & \\
e.max & 0 & 0 & 1.000 & & \\
InCoris & 0 & 0 & 0 & 1.000 & \\
Prettau & 0 & 0 & 0 & 0 & 1.000 \\
\hline
\end{tabular}

indicated that bleaching technique using 35\% hydrogen peroxide either without or with LED illumination resulted in significantly decreasing surface hardness of the ceramic materials compared with what was observed in the nonbleaching group $(\mathrm{p}<0.05)$, as preseneted in Table 5 . Bleaching ceramic materials using $35 \%$ hydrogen peroxide with LED illumination demonstrated significant more reduction in surface hardness than what was observed in the ceramic materials bleached without LED illumination $(\mathrm{p}<0.05)$, as shown in Table 5 . The bleaching technique using $35 \%$ hydrogen peroxide both with and without LED illumination resulted in the surface hardness reduction of ceramics for CAD/CAM as shown in Graph 1.

The scanning electron microscope photomicrographs of different ceramics materials treated with different bleaching techniques compared with those without bleached surfaces are shown in Figures 2A to O. It was seen that the ceramic specimen with no bleached surface showed an obviously flat surface appearance, as shown in Figures 2A, D, G, J, and M. The morphology of the bleached surface of the ceramic specimen that was exposed to $35 \%$ hydrogen peroxide per se showed minimal surface alteration compared with that shown by the nonbleached ceramic surface, as shown in Figures 2B, E, H, K, and N. The morphology of the bleached ceramic specimen on which $35 \%$ hydrogen peroxide was used with LED illumination appeared to have had an increase in surface irregularity and had a pitted appearance, as shown in Figures 2C, F, I, L, and O. Bleaching technique using 35\% hydrogen peroxide with LED illumination tends to demonstrate more irregularities in terms of the surface appearance of the ceramic than when bleaching is performed without LED illumination. The bleaching
Table 5: Tukey post hoc multiple comparisons of nanohardness of ceramic for CAD/CAM as a result of bleaching technique

\begin{tabular}{llll}
\hline & $\begin{array}{l}\text { No } \\
\text { bleaching }\end{array}$ & $\begin{array}{l}\text { Bleaching } \\
\text { without LED }\end{array}$ & $\begin{array}{l}\text { Bleaching } \\
\text { with LED }\end{array}$ \\
\hline No bleaching & 1.000 & & \\
Bleaching without LED & 0.010 & 1.000 & \\
Bleaching with LED & 0 & 0 & 1.000 \\
\hline
\end{tabular}

technique with $35 \%$ hydrogen peroxide with LED illumination demonstrated deterioration in the surface architecture of ceramic materials tested at different degrees of different ceramic materials.

\section{DISCUSSION}

The quality and the longevity of dental restoration are contingent on the physical, mechanical, and chemical properties of the materials. The diminution in surface hardness of the restorative material can induce irregularity on the surface as well as decrease the abrasion resistance of the material. ${ }^{18}$ The defect on the dental ceramic surface provokes crack propagation, leading to a fracture of the ceramic restoration. ${ }^{21}$ It is clearly evidenced that hydrogen peroxide possesses extensive diffusion capability. ${ }^{8}$ It is capable of inducing whitening effect by initiating the oxidation and reduction reaction through its free radicals. ${ }^{26}$ The hydrogen peroxides are able to segregate the polymer chain, especially at the site of double bonds, which are the most vulnerable parts of the restorative polymers. ${ }^{22}$ Since the free radicals prefer to attack at the interface between the inorganic filler and the resin matrix, this can cause those fillers to disintegrate from the material surface. ${ }^{19,23,26}$ Thus, a significant reduction in surface hardness and an increase in surface irregularities after bleaching was observed in case of Lava ${ }^{\mathrm{TM}}$ Ultimate and Vita Enamic ${ }^{\circledR}$ because both materials contain highly cross-linked polymer matrix and fine nano inorganic filler particles. The surface hardness and strength of the resin nano ceramic and hybrid ceramic are influenced by the amount and the type of inorganic fillers. Thus, the cleavage effect that hydrogen peroxide has on the resin matrix of these resin polymers is responsible for the decrease in 


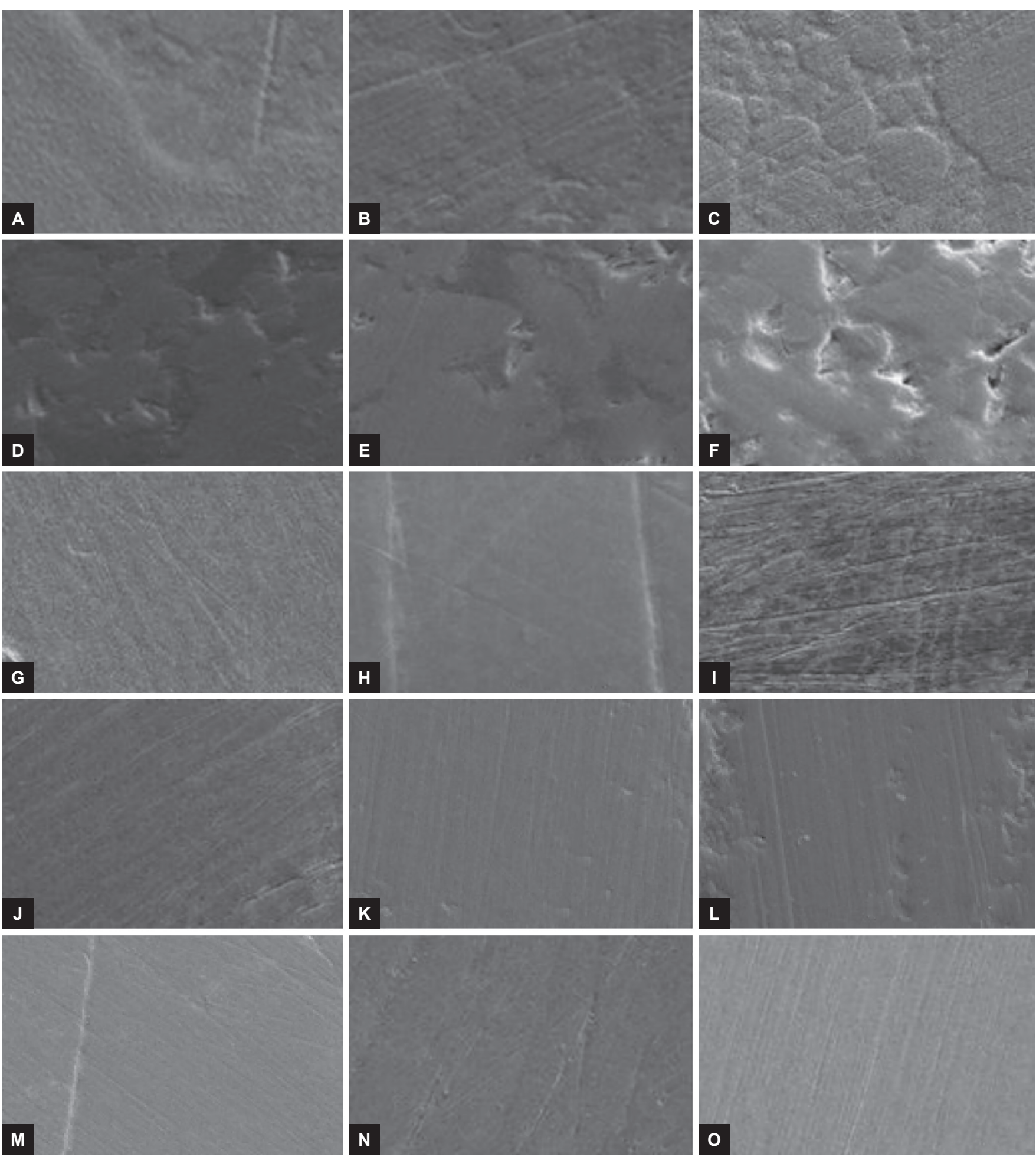

Figs 2A to O: Representative scanning electron microscope photomicrographs of surface characteristic of Lava Ultimate (A-C), Vita Enamic (D-F), IPS e.max CAD (G-I), InCoris TZI (J-L), and Prettau zirconia (M-O) on no bleaching (A, D, G, J, and M), bleach without $\operatorname{LED}(\mathrm{B}, \mathrm{E}, \mathrm{H}, \mathrm{K}$, and $\mathrm{N})$, and bleach with $\operatorname{LED}(\mathrm{C}, \mathrm{F}, \mathrm{I}, \mathrm{L}$, and $\mathrm{O})$ at original magnification, $\times 10 \mathrm{~K}$

surface hardness. The disintegration of inorganic fillers from the surface of the resin ceramic after the bleaching is responsible for the increasing surface aberration of Lava ${ }^{\mathrm{TM}}$ Ultimate and Vita Enamic ${ }^{\circledR}$ as witnessed in the scanning electron photomicrographs (Figs 2A to F).

The efficacy of the bleaching performed is related to the capability of the bleaching material to penetrate beyond the tooth surface. This also includes the ability of the bleaching material to penetrate through the restorative material. ${ }^{24}$ The stronger the restorative materials, the better would be the resistance to bleaching penetration. It is quite difficult for bleaching agents to diffuse beyond the surface and through the inner structure in case of strong materials. Thus, the bleaching 
effect only exhibits at the superficial surface. This explains the differences in the degree of surface alteration in the different tested ceramic materials. This can also be confirmed after scanning electron photomicrographs that reveal difference in the surface irregularity of the different tested ceramic materials (Figs 2A to O). The InCoris ${ }^{\circledR}$ TZI and Prettau ${ }^{\circledR}$ zirconia ceramics are mainly composed of oxide ceramics, which fall under strong ceramic materials. They are capable of resistance to surface corrosion from the bleaching agent. Slight surface alteration after bleaching with or without LED illumination was evidenced, as shown in the scanning electron photomicrographs (Figs 2J to O). The IPS e.max ${ }^{\circledR} \mathrm{CAD}$ is the lithium disilicate glass ceramic that contains mainly inorganic substance in its composition. The inorganic compositions in IPS e.max ${ }^{\circledR}$ CAD tend to be easily dissolvable by hydrogen peroxide bleaching agent. Thus, the microstructural appearance indicated significant surface irregularities after bleaching either with or without LED illumination. However, the surface alteration of lithium disilicate glass ceramic material after bleaching revealed less irregularity than the surface of the resin nano ceramic and hybrid ceramic, as was observed in the scanning electron photomicrographs (Figs 2G to I), which corresponds to the other study. ${ }^{22}$

This study was designed to simulate clinical environment and conditions, and thus, the bleaching technique was performed based on the manufacturer instruction according to the in-office bleaching technique. The ceramic samples were exposed to the bleaching product in the same manner as the tooth bleaching procedure recommended from the manufacturer. On the bleaching procedure, the specimens were stored in $37^{\circ} \mathrm{C}$ distilled water to simulate the cumulative effect of bleaching efficacy over time. It can be confirmed that the bleaching technique both with and without LED illuminations significantly affects the surface hardness of all-ceramic restorative materials compared with the baseline when no bleaching is used. Thus, the hypothesis was rejected. However, the bleaching technique with LED illumination exhibited more decrease in surface hardness than that without LED illumination for each of the ceramic materials tested. This indicated that bleaching with LED irradiation results in more reduction in the surface hardness of the ceramic dental material than when bleaching technique is implemented without LED illumination. This study indicated that LED illumination induces more bleaching efficacy, and thus, more reduction of the surface hardness and more deterioration of the surface.

\section{CONCLUSION}

The surface hardness is the particular property of each material that allows it to resist surface defects. The surface hardness of ceramic restorative materials depends on the nature of each ceramic material. Bleaching exhibited the diminution in the surface hardness of dental ceramics for CAD/CAM. The technique for bleaching affected the surface hardness of the ceramic materials tested. The technique of bleaching using 35\% hydrogen peroxide with LED illumination results in a higher decrease in surface hardness of the ceramic materials than what is observed in case of bleaching without LED illumination. The microscopic surface alterations on bleaching are significant in both resin nano ceramic and hybrid ceramic, and slightly microscopic surface alteration was exhibited with lithium disilicate ceramic materials, especially when bleaching was performed in conjunction with LED illumination. A minimal amount of microscopic surface alteration was observed on zirconia ceramics, which can possibly be deemed as negligible. The dentists should be aware of whether or not there is any ceramic restoration in the patient's mouth before performing the bleaching procedure on their patient. It is crucial to realize which type of ceramic material to be used for that restoration to avoid any undesirable effects on the existing restorations. Appropriate selection of bleaching technique as well as protection of the existing restoration should be considered.

\section{Clinical Significance}

Bleaching affects the hardness of ceramic restorative materials. Clinicians should make an informed careful choice about the type of material to be chosen for the existing restorations to avoid any undesirable effects. Appropriate selection of bleaching technique as well as protection of the existing restoration should be taken into account.

\section{REFERENCES}

1. Matis BA, Cochran MA, Franco M, Al-Ammar W, Eckert GJ, Stropes M. Eight in-office tooth whitening systems evaluated in vivo: a pilot study. Oper Dent 2007 Jul-Aug;32(4):322-327.

2. Haywood VB, Heymann HO. Night guard vital bleaching. Quintessence Int 1989 Mar;20(3):173-176.

3. Dahl JE, Pallesen U. Tooth bleaching - a critical review of the biological aspects. Crit Rev Oral Biol Med 2003;14(4):292-304.

4. Plotino G, Buono L, Grande NM, Pameijer CH, Somma F. Nonvital tooth bleaching: a review of the literature and clinical procedures. J Endod 2008 Apr;34(4):394-407.

5. Marson FC, Sensi LG, Vieira LC, Araújo E. Clinical evaluation of in-office dental bleaching treatments with and without the use of light-activation sources. Oper Dent 2008 Jan-Feb;33(1):15-22.

6. Zhang C, Wang X, Kinoshita J, Zhao B, Toko T, Kimura Y, Matsumoto K. Effects of KTP laser irradiation, diode laser, and LED on tooth bleaching: a comparative study. Photomed Laser Surg 2007 Apr;25(2):91-95.

7. Dadoun MP, Bartlett DW. Safety issues when using carbamide peroxide to bleach vital teeth-a review of the literature. Eur J Prosthodont Restor Dent 2003 Mar;11(1):9-13. 
8. Hanks CT, Fat JC, Wataha JC, Corcoran JF. Cytotoxicity and dentin permeability of carbamide peroxide and hydrogen peroxide vital bleaching materials, in vitro. J Dent Res 1993 May;72(5):931-938.

9. Attin T, Paqué F, Ajam F, Lennon AM. Review of the current status of tooth whitening with the walking bleach technique. Int Endod J 2003 May;36(5):313-329.

10. Friedman S, Rotstein I, Libfeld H, Stabholz A, Heling I. Incidence of external root resorption and esthetic results in 58 bleached pulpless teeth. Endod Dent Traumatol 1988 Feb;4(1):23-26.

11. Miyazaki T, Hotta $Y$, Kunii J, Kuriyama S, Tamaki Y. A review of dental CAD/CAM: current status and future perspectives from 20 years of experience. Dent Mater J 2009 Jan;28(1): 44-56.

12. Denry I, Kelly JR. Emerging ceramic-based materials for dentistry. J Dent Res 2014 Dec;93(12):1235-1242.

13. Yap AU, Wattanapayungkul P. Effects of in-office tooth whiteners on hardness of tooth-colored restoratives. Oper Dent 2002 Mar-Apr;27(2):137-141.

14. Attin T, Hannig C, Wiegand A, Attin R. Effect of bleaching on restorative materials and restorations-a systematic review. Dent Mater 2004 Nov;20(9):852-861.

15. Zaki AA, Fahmy NZ. The effect of a bleaching system on properties related to different ceramic surface textures. J Prosthodont 2009 Apr;18(3):223-229.

16. Ourique SA, Magdaleno JP, Arrais CA, Rodrigues JA. Effect of different concentrations of carbamide peroxide on microhardness of dental ceramics. Am J Dent 2011 Feb;24(1): 57-59.

17. Rosentritt M, Lang R, Plein T, Behr M, Handel G. Discoloration of restorative materials after bleaching application. Quintessence Int 2005 Jan;36(1):33-39.
18. Abu-Bakr N, Han L, Okamoto A, Iwaku M. Changes in the mechanical properties and surface texture of compomer immersed in various media. J Prosthet Dent 2000 Oct;84(4):444-452.

19. Bailey SJ, Swift EJ Jr. Effects of home bleaching products on composite resins. Quintessence Int 1992 Jul;23(7):489-494.

20. Anusavice KJ. Degradability of dental ceramics. Adv Dent Res 1992 Sep;6(1):82-89.

21. Yilmaz H, Aydin C, Gul BE. Flexural strength and fracture toughness of dental core ceramics. J Prosthet Dent 2007 Aug;98(2):120-128.

22. Türker SB, Biskin T. The effect of bleaching agents on the microhardness of dental aesthetic restorative materials. J Oral Rehabil 2002 Jul;29(7):657-661.

23. Chung KH. The relationship between composition and properties of posterior resin composites. J Dent Res 1990 Mar;69(3):852-856.

24. Yu H, Li Q, Hussain M, Wang Y. Effects of bleaching gels on the surface microhardness of tooth-colored restorative materials in situ. J Dent 2008 Apr;36(4):261-267.

25. Polydorou O, Hellwig E, Auschill TM. The effect of at-home bleaching on the microhardness of six esthetic restorative materials. J Am Dent Assoc 2007 Jul;138(7):978-984.

26. Wattanapayungkul P, Yap AU, Chooi KW, Lee MF, Selamat RS, Zhou RD. The effect of home bleaching agents on the surface roughness of tooth-colored restoratives with time. Oper Dent 2004 Jul-Aug;29(4):398-403.

27. Moraes RR, Marimon JL, Schneider LF, Correr Sobrinho L, Camacho GB, Bueno M. Carbamide peroxide bleaching agents: effects on surface roughness of enamel, composite and porcelain. Clin Oral Investig 2006 Mar;10(1):23-28.

28. Huja SS, Beck FM, Thurman DT. Indentation properties of young and old osteons. Calcif Tissue Int 2006 Jun;78(6):392-397. 